\title{
Malaria in Birmingham and a London teaching hospital
}

\author{
C J ELLIS, SUSANNAH J EYKYN， PRIMROSE WATKINS， MARILYN BELL, A M GEDDES
}

British Medical fournal, 1979, 1, 385-388

\section{Summary and conclusions}

During the past five years the incidence of imported malaria increased among patients seen in East Birmingham Hospital and in St Thomas's Hospital, London. Plasmodium vivax was the predominant species in Birmingham, and was almost always acquired by Asian immigrants visiting the Indian subcontinent. In St Thomas's $P$ falciparum was most commonly imported, usually by African immigrants visiting Nigeria and Ghana. Two patients (one Irish, one Japanese) died of falciparum malaria after visiting tropical Africa. In both hospitals the immigrant patients had seldom taken prophylactic drugs, and the few who had, ceased to do so on arrival in the UK and sometimes before leaving the malarious country.

Apparently immigrants who visit their homeland do not consult their general practitioners before travelling, are given inappropriate advice, or do not take appropriate advice when given.

Since the incidence of imported falciparum malaria in the UK is rising, the following points should be considered: the infection may be lethal, particularly in patients lacking immunity; it can mimic other diseases,

Department of Communicable and Tropical Diseases, East Birmingham Hospital, Birmingham B9 5ST

C J ELLIS, MB, MRCP, honorary senior registrar

PRIMROSE WATKINS, MB, MRCP, senior house officer

MARILYN BELL, medical student

A M GEDDES, MB, FRCP, consultant physician

Department of Microbiology, St Thomas's Hospital, London SE1 SUSANNAH J EYKYN, MB, MRCPATH, senior lecturer in clinical microbiology which may lead to delayed diagnosis; severe disease may be associated with few parasites on a blood film, and even if the result is negative further tests should be performed; clinicians and hospital pharmacists should be aware of the need to keep permanent stocks of parenteral chloroquine and quinine preparations.

\section{Introduction}

Regular surveillance by the Malaria Reference Laboratory has shown a striking increase in the incidence of imported malaria in the UK during the 'seventies. ${ }^{12}$ Since many cases are probably not reported, the reported figure of 1527 cases in 1977 is probably an underestimate. During the five years January 1968 to March 197370 patients with malaria were admitted to the East Birmingham Hospital, ${ }^{3}$ but in the next five years up to March 1978350 patients were admitted, representing a fivefold increase. At St Thomas's Hospital malaria was rarely seen before 1974; indeed, most junior doctors had never seen a case. Between December 1974 and June 197878 patients were admitted.

Since the East Birmingham Hospital serves an immigrant population very largely derived from the Indian subcontinent and St Thomas's Hospital one mainly derived from Africa we decided to review jointly all cases of malaria admitted to the two hospitals over a similar period.

\section{Patients and methods}

All patients with malaria who were admitted to the East Birmingham Hospital between March 1973 and March 1978, and to St Thomas's Hospital between December 1974 and June 1978 were included in the study. Malaria, which was not always suspected clinically, was diagnosed in every case by finding malarial parasites on a blood film and the identity of the parasite confirmed by the local expert in the East Birmingham Hospital and by the Malarial Reference Laboratory for all the cases in St Thomas's. 
The following details were recorded in each case: the species of malarial parasite; the age, sex, and ethnic origin of the patient; the geographical area where malaria was acquired; the length of residence in the UK for non-Europeans; and the interval between leaving the malarious zone and presentation to hospital. Patients were asked whether they had taken prophylactic drugs, and if so, when they had been discontinued, and we tried to find out how many patients had been referred by their general practitioners with a suspected diagnosis of malaria.

\section{Results}

Out of 350 patients with malaria who were admitted to the East Birmingham Hospital Plasmodium falciparum was identified in 31, $P$ vivax in $315, P$ malariae in one, and $P$ ovale in three. Two patients infected with $P$ falciparum were also infected with $P$ malariae. Out of 78 cases of malaria seen at St Thomas's, $P$ falciparum was identified in 55 (two deaths), $P$ vivax in $19, P$ malariae in three, and $P$ ovale in one. Seven patients infected with $P$ falciparum had a mixed infectionfive with $P$ malariae and two with $P$ ovale-and two patients with vivax malaria were also infected with $P$ malariae. Table I shows the ages and ethnic origins of the patients and the species of infecting parasite. Most cases of falciparum malaria at East Birmingham Hospital occurred in the third and fourth decade. Falciparum malaria at St Thomas's and vivax malaria at East Birmingham Hospital were distributed over a wider age range that included many children and teenagers. Twice as many men as women had vivax malaria at both hospitals. This was also the case for falciparum malaria at East Birmingham Hospital, while at St Thomas's twice as many women as men had falciparum malaria. Seven women with falciparum malaria at St Thomas's were pregnant, two presenting during labour. Malaria was diagnosed during the first trimester in only one patient; she did not abort. At East Birmingham Hospital 11 patients with vivax malaria were pregnant, and two of the five in whom malaria was diagnosed in the first trimester aborted.

More Europeans were admitted to East Birmingham Hospital with falciparum malaria, yet overall the proportion of patients with falciparum malaria who presented at St Thomas's was greater, though most were of African descent (table I). Table II shows the geographical areas where falciparum and vivax infections were acquired. The patients were classified as "natives"- those returning to a malarious country in which they were born-and "non-natives" -those who were born and grew up in a non-endemic area. There were 38 children ( 32 in East Birmingham Hospital, six in St Thomas's), classified as natives in table II, who were born in the UK to immigrant parents and then returned with their parents to their parents' country of origin, where they acquired malaria on their first visit. Thirty-three of these children were of Asian parentage (32 in East Birmingham Hospital, one in St Thomas's) and acquired $P$ vivax on the Indian subcontinent, and five (St Thomas's) were of African parentage and acquired $P$ falciparum in Africa. Most patients with falciparum malaria seen at East Birmingham Hospital were Europeans born in the UK who had visited a malarious country either

TABLE I-Distribution of patients with malaria admitted to East Birmingham Hospital (EBH) and St Thomas's Hospital (STH), according to species of infecting parasite, age, and ethnic origin. Total numbers of patients given in parentheses

\begin{tabular}{|c|c|c|c|c|c|c|c|c|}
\hline & \multicolumn{2}{|c|}{ P falciparum } & \multicolumn{2}{|c|}{$P$ vivax } & \multicolumn{2}{|c|}{$P$ malariae } & \multicolumn{2}{|c|}{ Povale } \\
\hline & $\begin{array}{c}\text { EBH } \\
(n=31)\end{array}$ & $\underset{(\mathbf{n}=55)}{\text { STH }}$ & $\begin{array}{c}\text { EBH } \\
(\mathbf{n}=315)\end{array}$ & $\underset{(n=19)}{\text { STH }}$ & $\underset{(n=1)}{E B H}$ & $\begin{array}{l}\text { STH } \\
(\mathrm{n}=3)\end{array}$ & $\begin{array}{c}\mathbf{E B H} \\
(\mathbf{n}=3)\end{array}$ & $\begin{array}{l}\mathrm{STH} \\
(\mathrm{n}=1)\end{array}$ \\
\hline $\begin{array}{r}0-10 \\
11-20 \\
21-30 \\
31-40 \\
41-50 \\
51-60 \\
61-70 \\
71-80\end{array}$ & $\begin{array}{r}5 \\
10 \\
11 \\
4 \\
1\end{array}$ & $\begin{array}{r}7 \\
7 \\
15 \\
21 \\
4 \\
1\end{array}$ & $\begin{array}{c}\text { Age by } \\
51 \\
71 \\
83 \\
47 \\
36 \\
15 \\
9 \\
3 \\
\text { Ethnic }\end{array}$ & $\begin{array}{r}\text { decade } \\
3 \\
2 \\
9 \\
1 \\
1 \\
2 \\
1 \\
\text { origin }\end{array}$ & 1 & 2 & $\begin{array}{l}1 \\
1 \\
1\end{array}$ & 1 \\
\hline $\begin{array}{l}\text { Indian } \\
\text { subcontinent } \\
\text { W Africa }\end{array}$ & 5 & 2 & 308 & 14 & & & 3 & \\
\hline $\begin{array}{l}\text { and Zaire } \\
\text { africa } \\
\text { and Zambia }\end{array}$ & 10 & $\begin{array}{r}44 \\
3\end{array}$ & 2 & 1 & 1 & 3 & & 1 \\
\hline $\begin{array}{l}\text { Europe } \\
\text { Middle East } \\
\text { Far East }\end{array}$ & $\begin{array}{r}14 \\
1\end{array}$ & 5 & $\begin{array}{l}4 \\
1\end{array}$ & 4 & & & & \\
\hline
\end{tabular}

TABLE II-Geographical area where patients with falciparum or vivax malaria who were admitted to St Thomas's or East Birmingham hospitals (STH; EBH) acquired their infections. Patients grouped according to whether they were natives of that area or not

\begin{tabular}{|c|c|c|c|c|c|c|}
\hline & $\begin{array}{l}\text { Indian } \\
\text { ubcontinent }\end{array}$ & W Africa & E Africa & SE Asia & S America & Total \\
\hline EBH $\left\{\begin{array}{l}\text { Native } \\
\text { Non-native }\end{array}\right.$ & e & $\begin{array}{l}P \text { falci } \\
11 \\
14\end{array}$ & $\begin{array}{r}\text { parum } \\
2\end{array}$ & & 1 & $\begin{array}{l}14 \\
17\end{array}$ \\
\hline STH $\left\{\begin{array}{l}\text { Native } \\
\text { Non-native }\end{array}\right.$ & & ${ }^{43} P_{2}$ & $\begin{array}{r}3 \\
4 \\
\text { tax }\end{array}$ & & & $\begin{array}{r}46 \\
9\end{array}$ \\
\hline EBH $\left\{\begin{array}{l}\text { Native } \\
\text { Non-native }\end{array}\right.$ & $\begin{array}{r}308 \\
3\end{array}$ & & 4 & & & $\begin{array}{r}308 \\
7\end{array}$ \\
\hline STH $\left\{\begin{array}{l}\text { Native } \\
\text { Non-native }\end{array}\right.$ & $\begin{array}{r}14 \\
3\end{array}$ & 1 & & 1 & & $\begin{array}{r}15 \\
4\end{array}$ \\
\hline
\end{tabular}

for business or on holiday, whereas those seen at St Thomas's were natives of malarious countries who lived in the UK and had acquired malaria on a visit to their home country. At East Birmingham Hospital 308 Indian-born Asians acquired vivax malaria on the Indian subcontinent, but three also acquired falciparum malaria there.

Table III shows the numbers of non-European patients with falciparum or vivax malaria who had arrived in the UK for the first time from a malarious country, and those who had been resident in the UK, in many cases for several years, before returning to an endemic zone. Of the 315 patients at East Birmingham Hospital with vivax malaria, 209 were resident in the UK before returning to India, as were eight of the 19 patients with vivax malaria seen at St Thomas's Hospital. Two-thirds of the Africans seen at St Thomas's with falciparum malaria had also lived in the UK.

TABLE III-Numbers of non-European patients with falciparum or vivax malaria zho had newly arrived in $U K$ from a malarious country or had been resident in $U K$ before returning to an endemic zone

\begin{tabular}{llcccccc}
\hline & & & \multicolumn{2}{c}{$P$ falciparum } & & \multicolumn{2}{c}{ P vivax } \\
& & & EBH & STH & & EBH & STH \\
\hline Resident in UK & $\ldots$ & $\cdots$ & 6 & 34 & & 209 & 7 \\
New arrivals $\ldots$ & $\ldots$ & $\cdots$ & 8 & 16 & & 99 & 8 \\
\hline & Total & & 14 & 50 & & 308 & 15
\end{tabular}

EBH $=$ East Birmingham Hospital
STH $=$ St 'Thomas's Hospital.

The interval between leaving the country where malaria was acquired and the diagnosis of the disease is shown in the figure for patients infected with $P$ falciparum and $P$ vivax. Most patients had symptoms of malaria for several days before a parasitological diagnosis was made and treatment given. There was no obvious seasonal incidence for falciparum malaria, but 189 of the patients with vivax malaria $\left(60^{\circ}{ }_{0}\right)$ seen at East Birmingham Hospital were admitted between the beginning of May and the end of August.

Roughly three-quarters of all patients with malaria admitted to the Infectious Diseases Unit at East Birmingham Hospital had been referred by their general practitioner with a letter stating that malaria was a probable diagnosis. At St Thomas's many patients with malaria presented to the casualty department without a letter of referral, but of those who had such a letter, malaria was suggested as a possible diagnosis in about half of them. In three cases malaria was diagnosed after open-heart surgery, in seven by obstetricians, in one by the department of genitourinary medicine, and in one by ENT surgeons. One African doctor diagnosed himself while working on the medical unit.

Table IV shows the number of patients with falciparum and vivax malaria who took prophylactic antimalarial drugs. "Full prophylaxis" meant that the patient had taken an appropriate drug regularly while abroad and for at least four weeks after leaving the malarial zone. Any other regimen was classified as inadequate. Thirty-four of the 55 patients admitted to St Thomas's Hospital with falciparum malaria took no antimalarial prophylactic drugs and in all but one of the others prophylaxis was inadequate. Only two of the 308 non-Europeans with 


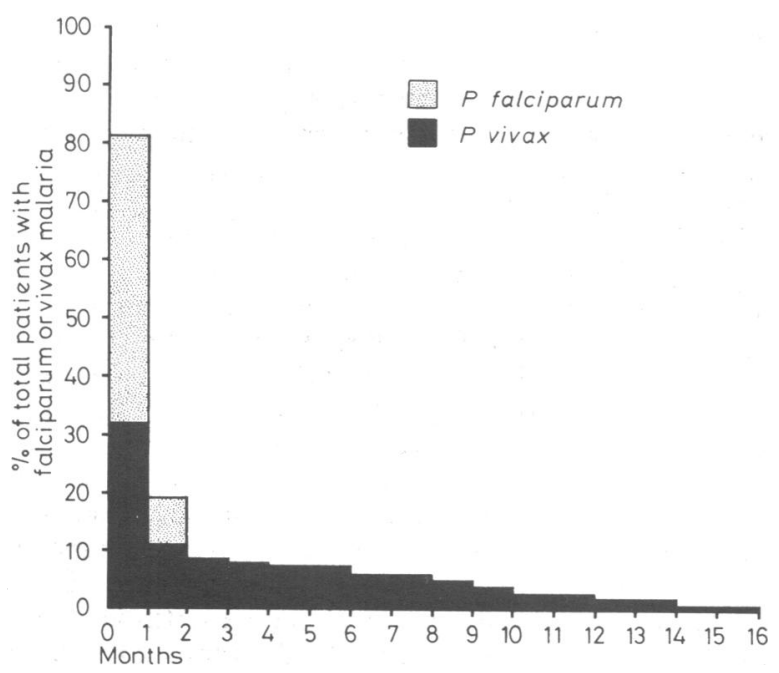

Interval in months between leaving endemic zone and diagnosis of malaria in patients infected with $P$ falcipurum and $P$ vivax.

TABLF IV-Numbers of native and non-native patients with falciparum and vivax malaria who took prophylactic antimalarial drugs

\begin{tabular}{l}
\hline \\
\cline { 3 - 5 }
\end{tabular}

EBH $=$ East Birmingham Hospital.
STH $=$ St Thomas's Hospital.

vivax malaria at East Birmingham Hospital had taken preventive treatment, and that was inadequate.

\section{Case reports}

The following case reports illustrate particular points.

FATAL FALCIPARUM MALARIA

Case 1-A 48-year-old Irishman had been working as a pipeliner in Kenya since November 1976. Despite repeated advice from his company to take prophylactic drugs he failed to do so, and had been treated for malaria in Nairobi in May 1977. After this attack he was sent home to convalesce, arriving in London on 10 June. He became unwell with high fever and headache on 17 June, and when seen by his general practitioner on 20 June he'was semi-comatose. Blood films on admission to St Thomas's Hospital showed a parasitaemia of $1 \%-2 \%$, with $P$ falciparum as the infecting species, and cerebral malaria was diagnosed. He was treated with intravenous chloroquine ( $300 \mathrm{mg}$ eight-hourly) and then intravenous quinine $(600 \mathrm{mg}$ 12-hourly), but died 36 hours later. At necropsy the classical appearance of cerebral malaria was seen in the brain.

Case 2-A 43-year-old Japanese business man had been working for two and a half years in Mozambique, where he had been taking prophylactic antimalarial drugs until March 1978, when he was told by a local doctor that it was no longer necessary. He arrived in London on 17 June, and the next day began to feel unwell, with vomiting and fevers. On 22 June he was noticeably jaundiced when seen in a private medical clinic, and was referred to St Thomas's Hospital with a presumptive diagnosis of hepatitis. Malaria was considered as a likely diagnosis in the casualty department, and when blood films were examined a $30 \%-40 \%$ parasitaemia with $P$ falciparum was found. Although the patient was fully conscious and rational when chloroquine treatment was started, within four hours he became semi-comatose and a few hours later had a cardiac arrest. Despite resuscitative measures and intravenous quinine (600 $\mathrm{mg}$ eight-hourly) he died 48 hours later. No necropsy was performed.

\section{"LASSA" SCARE}

Case 3-A 37-year-old Nigerian accountant, who had lived in London for 14 years, became unwell with fever and headache on the aeroplane when returning to London after a month's visit to Nigeria. He had taken no prophylactic antimalarial drugs. When first seen in the casualty department at St 'Thomas's two days later he was given ampicillin and then tetracycline. Five days later when still unwell he was again seen in the casualty department, when malaria was thought to be the likely diagnosis, but since he had been up country in Nigeria and visited hospitals with his brother, a doctor, the possibility of Lassa fever was also considered. Unfortunately, malaria parasites were not seen on the thin film, and before a thorough search of the thick film could be conducted a full scale Lassa-type alert was begun and the patient was transferred to Coppetts Wood Hospital and put in a Trexler isolator. He was treated with chloroquine, clinical improvement was rapid and subsequent examination of the thick film at St Thomas's Hospital showed extremely scanty rings of $P$ falciparum.

OPEN-HEART SURGERY

Cases 4-6-These three Tanzanian girls came to the UK from Tanzania for open-heart surgery. Each patient developed a swinging fever after operation, and $P$ falciparum, in one case with $P$ malariae, was found on blood films. The diagnosis was not made for some days in the first patient, since fever is so common after open-heart surgery. These cases have been fully described already.

\section{Discussion}

The number of cases of malaria in the UK reported to the Reference Laboratory" has risen from 662 in 1974 to 1527 in 1977 , and the total of 1130 for 1978 (to 25 July) suggests that the overall figure for 1978 may increase further. We have noticed a similar, possibly even more striking increase at our two hospitals. Roughly $80^{\circ}$ " of the reported cases of malaria in the UK are caused by vivax infections and $15^{\circ}{ }_{0}$, by falciparum. East Birmingham Hospital seems to mirror this general pattern, with 315 of their 350 patients $\left(90^{\circ}{ }_{0}\right)$ being infected with $P$ vivax and $31\left(9^{\circ}{ }^{\circ}\right)$ with $P$ falciparum. The pattern is reversed, however, at St Thomas's Hospital, where 55 of the 78 patients $\left(70^{\circ}{ }_{0}\right)$ were infected with $P$ falciparum, including two who died, and only $19\left(24^{\circ}{ }_{0}\right)$ with $P$ vivax. This interesting difference in species between St Thomas's Hospital and not only East Birmingham Hospital but the rest of the UK may be explained by the fact that the local immigrant population of St Thomas's that is exposed to malaria is predominantly African, and these people visit tropical Africa where $P$ falciparum is more common than $P$ vivax. At East Birmingham Hospital, however, the immigrant population originates almost exclusively from the Indian subcontinent, and they acquire vivax malaria in India, Pakistan, and Bangladesh where this species predominates.

Nevertheless, three cases of falciparum malaria acquired in India were seen in East Birmingham Hospital, and WHO report an appreciable increase in the incidence of falciparum malaria in Bangladesh, India, and Sri Lanka (557 701 cases were reported in 1976). ${ }^{5}$ Most patients with falciparum malaria had been infected in Nigeria or Ghana, which reflects the overall pattern for the UK. ${ }^{2}$ Roughly $80 \%$ of patients with falciparum malaria presented within four weeks of leaving the malarial zone, many within a few days, and some the day they arrived in the UK (see figure). Patients with vivax malaria tended to present later, sometimes many months after leaving an endemic zone.

At both hospitals most patients with malaria were immigrants, either new arrivals in the UK or, more commonly, British residents who had visited their country of origin, often taking children who had been born in the UK and who were visiting their parents' country of origin for the first time. Some of these immigrants had lived in the UK for many years before returning home. They would therefore have lost most of their protective immunity to malaria acquired by continual exposure to the parasite in hyperendemic areas. Such immunity can effectively curtail the clinical features of the disease, despite the persistence of relatively dense parasitaemia. ${ }^{6}$ More importantly, perhaps, children born in the UK of such parents would have no im- 
munity to the disease, making them as susceptible as a nonimmune European. At East Birmingham Hospital twice as many men as women acquired malaria, but in the earlier series reported from this hospital ${ }^{3}$ there were nine times as many men as women. These figures suggest that increasing numbers of Asian women have now joined their husbands in the UK and are also making visits home to India and Pakistan. At St Thomas's Hospital falciparum malaria is twice as common in female as male immigrants, though the figures are much smaller.

It is commendable that malaria in Birmingham is so often diagnosed by the patient's referring general practitioner. At St Thomas's Hospital the local general practitioners seemed less likely to suggest malaria as the diagnosis, often referring the patient as a case of fever of unknown origin or for investigations such as the Paul-Bunnell test and blood counts. At St Thomas's Hospital not all patients are referred by their general practitioners, as is customary at East Birmingham Hospital, many present to the casualty department, sometimes with no general practitioner's letter, indeed sometimes they have no general practitioner, and thus in many patients malaria is diagnosed in the casualty department.

Overall, many immigrant patients failed to take adequate prophylactic treatment-most took none at all, and of those that had taken any, none had taken the drugs for four weeks after leaving the malarious zone. These patients probably do not consult their general practitioners when planning a trip home, are given inappropriate advice, or do not take appropriate advice when given. This implies a lack of communication, for which the local general practitioners, travel agents, and the airlines must to some extent be held responsible. Non-natives (mostly Europeans) were much more likely to have taken prophylactic drugs than natives, but only six of them had taken a full course (table IV).

The two deaths from falciparum malaria seen at St Thomas's Hospital emphasise that this infection may be lethal, particularly in patients lacking immunity. The following points are worth mentioning. Firstly, falciparum malaria can mimic other diseases, which may lead to delay in diagnosis; this is well illustrated by the patient (case 2) who was referred to St Thomas's Hospital after he had been seen in another clinic, where hepatitis was diagnosed. Secondly, while many clinicians know of the incipient dangers of the presence of many falciparum parasites in the blood, not all are aware that severe disease may be associated with few parasites on a blood film. A case of fatal falciparum malaria was recently reported in the USA in which blood films on the first and second days of admission to hospital contained no malarial parasites at all. ${ }^{\top}$ The relatively low-grade parasitaemia in one of our patients (case 1) led the clinicians to perform a lumbar puncture to eliminate other causes of coma. Thirdly, on a practical note, we should mention that when this patient (case 1) presented to the casualty department the hospital pharmacy held neither intravenous chloroquine nor quinine in stock, and this deficiency delayed effective treatment. The increasing incidence of falciparum malaria in the UK should alert clinicians and hospital pharmacists to the need to keep such parenteral preparations permanently in stock.

Clinical suspicion of malaria should not be dampened by a negative report on a single blood film. Further blood films should be examined twice daily for one to two days, but this need not interfere with early treatment. "Such action was undertaken in one case (No 3) but not before the patient had been moved to special isolation facilities for suspected Lassa fever. Malaria may well be overlooked when exotic diseases are also a possibility.

The stress of major surgery in patients who have newly arrived in the UK from endemic countries may lead to a recrudescence of latent falciparum malaria, as in cases 4-6. Each patient had a heavy parasitaemia and prominent symptoms. Although this is well recognised in the tropics it was a most unexpected complication of open heart surgery in a London teaching hospital.

We thank Professor H V Morgan for identifying the parasites and clinical advice for patients at East Birmingham Hospital; the many clinicians in St Thomas's Hospital for permission to study their patients; Dr B Southgate and Mr P Sargeaunt of the Malaria Reference Laboratory for their continued invaluable help; and Mrs C Botterill for expert technical help in St Thomas's Hospital.

Requests for reprints should be addressed to S J Eykyn.

\section{References}

${ }^{1}$ Bruce-Chwatt, L J, Southgate, B A, and Draper, C C, British Medical fournal, 1974, 2, 707.

2 Malaria Reference Laboratory, London School of Hygiene and Tropical Medicine. Personal communication.

3 Ansdell, V E, et al, British Medical fournal, 1974, 2, 206.

4 Eykyn, S J, and Braimbridge, M V, Lancet, 1977, 2, 411.

- World Health Organisation, Malaria Control Strategy, unpublished mimeographed document, WHO A31/19, 1978.

${ }^{6}$ McGregor, I A, British Medical Bulletin, 1972, 28, 22.

Center for Disease Control, Malaria Surveillance Annual Summary, 1976. Atlanta, Georgia, September 1977.

* Bruce-Chwatt, L J, Lancet, 1970, 2, 143.

(Accepted 13 October 1978)
Could you provide guidelines for examining employees of a building firm who handle asbestos?

There are four main consequences of asbestos dust inhalation. Pleural plaques, which may or may not be calcified. These indicate asbestos exposure and, in themselves, are not a cause of disability. Asbestosis, which is an interstitial fibrosis, most commonly occurring after several years' exposure to asbestos dust in conditions unacceptable by today's standards. In fully established cases there may be some or all of the following: breathlessness, finger clubbing, late basal inspiratory crackles, and defective gas transfer. Radiological changes are seldom pronounced, but there may be decreased translucency of lung bases, or more pronounced opacities characteristic of interstitial fibrosis, which may cause the appearance of a "shaggy" heart border. Carcinoma of bronchus - In those with asbestosis or with fairly heavy exposure to asbestos there is an increased incidence of bronchial carcinoma, most severe in the case of cigarette smokers. Mesothelioma of pleura-This relatively rare tumour is most commonly found in those who have been exposed to asbestos, sometimes as long as 30 or 40 years previously. The exposure does not have to be great, appreciably less than would be required to cause detectable asbestosis. The crocidolite (blue) form of asbestos is considerably more hazardous in respect of mesothelioma than other forms of the material. Although it is no longer used in Britain, some crocidolite may be present in old asbestos lagging and partitions, posing a health risk during dismantling operations.

Medical examinations should be done only as a back-up to the more important general and personal protective measures that are now statutorily required. Examination would usually consist of history taking, clinical examination, and chest radiograph (PA view routinely, but oblique views if a better view of pleural changes is desired). Simple spirometry (as by Vitalograph) may be used to monitor progress and might give indications of a developing restrictive condition. Tests for gas transfer would be of added value if there were other indications of asbestosis. Even when current working conditions are satisfactory, there may be older men who have previously worked as, say, laggers, under worse conditions. Initial radiographs and lung function tests serve as reference baselines and to exclude other conditions. It is best to exclude from work with asbestos those with appreciable chest or heart disease, and also those with rheumatoid disease or polyarthritis as they are more prone to develop pulmonary fibrosis. As to follow-up tests (six-monthly, annually, or every two years depending on circumstances), the earliest evidence of asbestosis is seldom radiological, and finding early radiological evidence of mesothelioma is unlikely to affect the prognosis.

Health and Safety Executive, Asbestos, Medical Series 13. HMSO, 1977. 